\title{
Aldol Condensation-Type of Group Transfer Polymerization of 1-Butadienyloxytrimethylsilane and 3-Substituted-1- butadienyloxytrimethylsilanes: Different Polymerizability of Geometrical Isomers
}

\author{
Hiroshi Sumi, Kenji Haraguchi, Yoshihito InaI, \\ Tadamichi HiRabayashI, and Kenji YoKota \\ Department of Materials Science and Engineering, \\ Nagoya Institute of Technology, \\ Gokiso-cho, Showa-ku, Nagoya 466, Japan
}

(Received May 13, 1994)

\begin{abstract}
The aldol condensation-type of group transfer polymerization (aldol-GTP) of $E$ - and $Z$-isomers of 1-butadienyloxytrimethylsilane (BdTMS), 3-methyl-1-butadienyloxytrimethylsilane (MeBdTMS), and 3-phenyl-1-butadienyloxytrimethylsilane (PhBdTMS) was examined in the presence of $p$-anisaldehyde as an initiator and $\mathrm{ZnBr}_{2}$ as a catalyst. $E$-Isomers were rapidly polymerized to yield their polymers with a fairly narrow molecular weight distribution $\left(M_{w} / M_{\mathrm{n}}=1.2-1.3\right)$, while $Z$-isomers could not be at all. $E$-BdTMS was treated with excess benzaldehyde in the presence of a small amount of $\mathrm{ZnBr}_{2}$ to yield an $1: 1$ aldol adduct. However, $Z$-BdTMS reacted slower than E-BdTMS under the same conditions. The different behavior between geometrical isomers suggests that propagation of aldol-GTP proceeds by way of a bicyclic transition state, in which only the $E$-isomer must be fit for stereochemical requirement.

KEY WORDS Group Transfer Polymerization / Aldol Condensation / 1-Butadienyloxytrimethylsilane / 3-Methyl-1-butadienyloxytrimethylsilane / 3-Phenyl-1-butadienyloxytrimethylsilane / Geometrical Isomer / Transition State /
\end{abstract}

Aldol condensation-type of group transfer polymerization (aldol-GTP) of silyl dienyl ethers has been explored ${ }^{1}$ with 1-butadienyloxytrimethylsilane (BdTMS), of which polymerization in the presence of benzaldehyde as an initiator and Lewis acid as a catalyst in benzene yielded polymers with relatively narrow molecular weight distribution. In subsequent studies, it was found that $p$ anisaldehyde ${ }^{2}$ and $\mathrm{ZnBr}_{2}{ }^{3}$ were the most effective for regulation of polymer molecular weight. Furthermore, it was found that a polymerization mixture could be made homogeneous by using of a small amount of diethyl ether with toluene even at $-78^{\circ} \mathrm{C} .^{4,5}$ Since undesired side reactions (e.g., DielsAlder addition) were almost extinguished in the last system, the molecular weight of the polymer was close to that calculated from the initial concentration ratio of monomer to initiator and $M_{w} / M_{n}$ was within 1.3 , even when
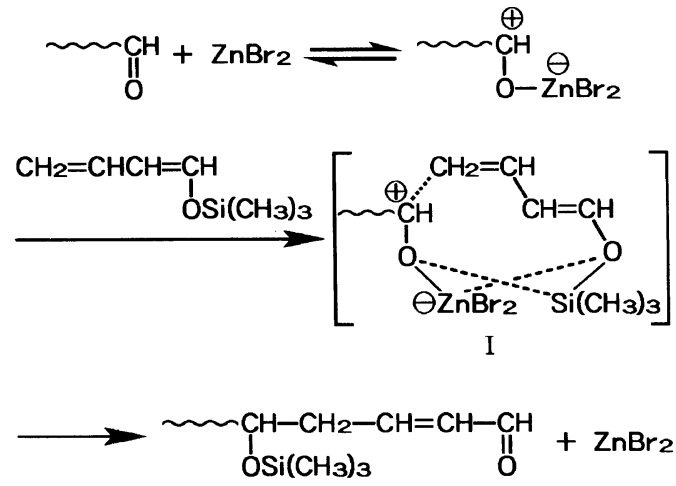

Scheme 1. 
the ratio was more than 300 .

Geometrical effect of $E$ - and Z-BdTMS on the aldol-GTP has been never discussed so far, despite propagation as well as initiation for aldol-GTP of BdTMS were tentatively assumed to pass through a transition state $I$ in Scheme 1. Because $E$-isomer could be prepared in purity of about $95 \%$ by the method of Danishefsky, ${ }^{6}$ significant effects were not observed.

On the assumption that a bicyclic transition state is required for propagation, different polymerizabilities of two geometrical isomers of BdTMS should be observed on the aldol-GTP. On the contrary, if propagation of aldol-GTP proceeds stepwise during which configuration of incoming monomer changes without difficulty, the geometry of the monomer should not be significant.

This paper deals with the behavior of two geometrical isomers of BdTMS or its derivatives for aldol-GTP, and demonstrates the validity of the bicyclic transition state model.
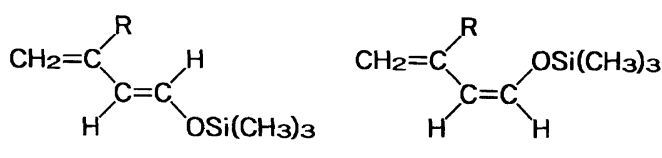

$\begin{array}{lll}\text { E-BdTMS } & (\mathrm{R}=\mathrm{H}) & Z \text {-BdTMS } \quad(\mathrm{R}=\mathrm{H}) \\ \text { E-MeBdTMS }\left(\mathrm{R}=\mathrm{CH}_{3}\right) & Z \text {-MeBdTMS }\left(\mathrm{R}=\mathrm{CH}_{3}\right) \\ \text { E-PhBdTMS }\left(\mathrm{R}=\mathrm{C}_{6} \mathrm{H}_{5}\right) & Z \text {-PhBdTMS }\left(\mathrm{R}=\mathrm{C}_{6} \mathrm{H}_{5}\right)\end{array}$

\section{EXPERIMENTAL}

\section{Monomers}

BdTMS was prepared from trimethylchlorosilane and crotonaldehyde according to the procedures described in previous papers ${ }^{1,2}$ $(E / Z=95 / 5)$. Pure $E$-BdTMS was isolated by repeating fractional distillation. bp $62^{\circ} \mathrm{C} / 65$ $\mathrm{mmHg}$.

$Z$-BdTMS was prepared according to the method given in the literature, ${ }^{7} 2$-phenyl-1,3dioxacyclohept-5-ene was prepared from benzaldehyde and cis-2-butene-1,4-diol in $82 \%$ yield. bp $64^{\circ} \mathrm{C} / 0.3 \mathrm{mmHg}$. $n$-Butyllithium (1.64 moll $1^{-1}$ solution in $n$-hexane) was added to 2-phenyl-1,3-dioxacyclohept-5-ene in tetra- hydrofuran at $-78^{\circ} \mathrm{C}$. The mixture was stirred for $1 \mathrm{~h}$ at $-78^{\circ} \mathrm{C}$, and then for $1 \mathrm{~h}$ at room temperature. Trimethylchlorosilane was added dropwise to the mixture at room temperature. The mixture was stirred for $8 \mathrm{~h}$ at room temperature. A white precipitate was filtered through a sintered glass disk and washed with diethyl ether. The filtrate was distilled to remove the solvent and unchanged components. The residue was fractionally distilled under reduced pressure to give Z-BdTMS in $73 \%$ yield. bp $64^{\circ} \mathrm{C} / 75 \mathrm{mmHg}$. Purity was checked by gas chromatography.

MeBdTMS was prepared from trimethylchlorosilane and 3-methyl-2-butenal in a similar manner to the synthesis of BdTMS in $85 \%$ yield $(E / Z=85 / 15)$. bp $73^{\circ} \mathrm{C} / 43$ $\mathrm{mmHg}$. Fractional distillation of the prepared MeBdTMS gave pure $E$-MeBdTMS as a fraction with a higher boiling point. A fraction with lower boiling point contained more than $50 \% Z$-isomer. The lower boiling point fraction was treated with maleic anhydride in benzene. Only $E$-MeBdTMS in the fraction reacted with maleic anhydride to give an DielsAlder adduct. Z-MeBdTMS was obtained by distillation under reduced pressure after removal of the adduct, including 16\% 3-methyl1-trimethylsiloxy-2-butene as an impurity. ZMeBdTMS was used for polymerization without removal of the impurity.

PhBdTMS was prepared in a similar manner to the synthesis of BdTMS. $\beta$-Methylcinnamaldehyde ${ }^{8}$ was prepared from $\alpha$-methylstyrene and an equimolar amount of phosphorus oxychloride in $\mathrm{N}, \mathrm{N}$-dimethylformamide, and obtained in $46 \%$ yield. bp $76^{\circ} \mathrm{C} / 0.4$ $\mathrm{mmHg}$. The product was a mixture of $E$ - and $Z$ - $\beta$-methylcinnamaldehyde $(E / Z=70 / 30)$. The mixture of isomers was used in next reaction as it was, because sufficient separation of the isomers was not easy by fractional distillation. $\beta$-Methylcinnamaldehyde in benzene was mixed with triethylamine and catalytic amount of $\mathrm{ZnCl}_{2}$ at $30^{\circ} \mathrm{C}$. Trimethylchlorosilane was added dropwise to the mixture. The mixture 


\section{H. SuMi et al.}

(a)

Table I. ${ }^{1} \mathrm{H}$ NMR chemical shifts and coupling constants of BdTMS, MeBdTMS, and PhBdTMS ${ }^{\mathrm{a}}$

\begin{tabular}{llllcll}
\hline & \multicolumn{5}{c}{ Chemical shift/ppm } \\
\cline { 2 - 7 } & $\mathrm{H}^{1}$ & $\mathrm{H}^{2}$ & $\mathrm{R}^{3}$ & $\mathrm{H}^{4}$ & $\mathrm{H}^{5}$ & $\mathrm{H}^{6}$ \\
\hline E-BdTMS & 6.56 & 5.74 & 6.24 & 4.84 & 5.00 & 0.21 \\
Z-BdTMS & 6.19 & 5.25 & 6.76 & 4.91 & 5.09 & 0.22 \\
E-MeBdTMS & 6.51 & 5.83 & 1.80 & 4.70 & 4.76 & 0.20 \\
Z-MeBdTMS & 6.16 & 4.97 & 1.99 & 4.76 & 5.00 & 0.20 \\
E-PhBdTMS & 6.48 & 6.00 & $7.28-7.46$ & 5.11 & 4.95 & 0.18 \\
Z-PhBdTMS & 6.45 & 5.21 & $7.28-7.46$ & 5.79 & 5.44 & 0.17
\end{tabular}

(b)

\begin{tabular}{|c|c|c|c|c|c|c|c|c|c|c|}
\hline \multirow{2}{*}{ Monomer } & \multicolumn{10}{|c|}{ Coupling constant $/ \mathrm{Hz}$} \\
\hline & $J_{12}$ & $J_{13}$ & $J_{14}$ & $J_{15}$ & $J_{23}$ & $J_{24}$ & $J_{25}$ & $J_{34}$ & $J_{35}$ & $J_{45}$ \\
\hline$E$-BdTMS & 11.8 & 0.8 & 0.8 & - & 11.0 & 0.8 & 0.8 & 10.3 & 16.8 & 2.0 \\
\hline$Z$-BdTMS & 5.8 & 1.0 & 0.8 & - & 10.6 & 0.8 & 0.8 & 10.6 & 17.0 & 2.2 \\
\hline$E$-MeBdTMS & 12.0 & - & - & - & - & - & - & - & - & 0.6 \\
\hline$Z$-MeBdTMS & 6.4 & - & - & - & - & - & - & - & - & 0.6 \\
\hline$E$-PhBdTMS & 11.4 & - & 0.3 & - & - & 0.8 & - & - & - & 1.9 \\
\hline Z-PhBdTMS & 6.6 & - & 0.6 & 0.8 & - & 0.6 & 0.8 & - & - & 2.1 \\
\hline
\end{tabular}

a Numbering of BdTMS, MeBdTMS, and PhBdTMS<smiles>[R]/C(C=C)=C/COC</smiles>

$\mathrm{R}^{3}=\mathrm{H}$ for BdTMS, $\mathrm{R}^{3}=\mathrm{CH}_{3}$ for MeBdTMS, and $\mathrm{R}^{3}=\mathrm{C}_{6} \mathrm{H}_{5}$ for PhBdTMS.

Table II. ${ }^{13} \mathrm{C}$ NMR chemical shifts of BdTMS, MeBdTMS, and PhBdTMS ${ }^{\mathrm{a}}$

\begin{tabular}{lccrrr}
\hline Monomer & $\mathrm{C}^{\mathbf{1}}$ & $\mathrm{C}^{2}$ & $\mathrm{C}^{3}$ & $\mathrm{C}^{4}$ & $\mathrm{C}^{5}$ \\
\hline E-BdTMS & 145.2 & 115.0 & 133.8 & 112.6 & 0.2 \\
$Z$-BdTMS & 140.4 & 112.4 & 130.4 & 113.8 & 0.1 \\
E-MeBdTMS & 142.0 & 117.0 & 140.2 & 112.5 & 0.1 \\
$Z$-MeBdTMS & 139.5 & 112.1 & 141.0 & 113.5 & -0.1 \\
E-PhBdTMS & 144.9 & 115.6 & 145.9 & 115.6 & 0.1 \\
$Z$-PhBdTMS & 141.6 & 109.2 & 143.5 & 112.5 & -0.1 \\
\hline
\end{tabular}

a Numbering of BdTMS, MeBdTMS, and PhBdTMS<smiles>[R]/C(C=C)=C/C=C</smiles>

$\mathrm{R}^{3}=\mathrm{H}$ for BdTMS, $\mathrm{R}^{3}=\mathrm{CH}_{3}$ for MeBdTMS, and $\mathrm{R}^{3}=\mathrm{C}_{6} \mathrm{H}_{5}$ for PhBdTMS.

was stirred for $10 \mathrm{~h}$, keeping the temperature below $50^{\circ} \mathrm{C}$. A white precipitate was filtered through a sintered glass disk and washed with diethyl ether. The solvent and unchanged components were evaporated. The residue was fractionally distilled under reduced pressure to 
give $\mathrm{PhBdTMS}(E / Z=55 / 45)$ in $63 \%$ yield. bp $63-64^{\circ} \mathrm{C} / 0.4 \mathrm{mmHg}$.

${ }^{1} \mathrm{H}$ and ${ }^{13} \mathrm{C}$ NMR data of three monomers are summarized in Tables I and II, respectively.

\section{Materials}

$\mathrm{ZnBr}_{2}$ was sublimed in vacuo at appropriate temperature. $p$-Anisaldehyde (AAld) was fractionally distilled immediately before use. Toluene, benzene, and diethyl ether were purified by a conventional method and dried over sodium, distilled just prior to each polymerization.

\section{Procedures of Aldol-GTP}

Homogeneous Method. In a dry glass tube equipped with a septum, the monomer and toluene were mixed under nitrogen atmosphere and stirred. Polymerization was initiated by adding a solution of AAld, $\mathrm{ZnBr}_{2}\left(1.4 \mathrm{moll}^{-1}\right.$ solution in diethyl ether), and toluene via a syringe. After an adequate period, a mixture of methanol and triethylamine was added. The reaction mixture was washed with $5 \%$ aqueous sodium hydrogencarbonate solution and with water. The organic layer was dried over magnesium sulfate and concentrated in vacuo to give a product polymer. Conversion of the monomer was determined by gravimetry of the product polymer.

Heterogeneous Method. In a dry glass tube equipped with a septum, solid $\mathrm{ZnBr}_{2}$, AAld, and toluene were mixed under nitrogen atmosphere and stirred. The monomer was added to the mixture via a syringe. After an adequate period, the reaction mixture was filtered through a sintered glass disk to remove $\mathrm{ZnBr}_{2}$, and the filtrate was concentrated in vacuo to give a product polymer.

\section{1: 1 Aldol Adduct of BdTMS and Benzaldehyde}

In a $50 \mathrm{ml}$ flask equipped with a septum, $\mathrm{ZnBr}_{2}(0.25 \mathrm{~g}, 1.1 \mathrm{mmol})$, benzaldehyde (6.0 $\mathrm{ml}, 59 \mathrm{mmol})$, and benzene $(2.0 \mathrm{ml})$ were mixed under nitrogen atmosphere, and stirred until $\mathrm{ZnBr}_{2}$ was dissolved. E-BdTMS $(2.0 \mathrm{ml}$,
$11 \mathrm{mmol}$ ) was added to the mixture via a syringe. The mixture was stirred for $1 \mathrm{~h}$ at $20^{\circ} \mathrm{C}$. Subsequent procedures were similar to that of the homogeneous polymerization. After fractional distillation, $1.3 \mathrm{~g}$ of 5-phenyl-5-trimethylsiloxy-2-pentenal (1:1 aldol adduct of BdTMS and benzaldehyde) was obtained in $48 \%$ yield. bp $99-103^{\circ} \mathrm{C} / 0.4 \mathrm{mmHg} .{ }^{1} \mathrm{H}$ NMR $\left(\mathrm{CDCl}_{3}\right): \delta$ in ppm from $-\mathrm{Si}\left(\mathrm{CH}_{3}\right)_{3}: 0.00(\mathrm{~s}$, $\left.9 \mathrm{H}, \mathrm{SiCH}_{3}\right), 2.67$ and $2.71\left(\mathrm{~m}, 2 \mathrm{H}, \mathrm{CH}_{2}\right), 4.78$ $(\mathrm{dd}, J=7.0,5.2 \mathrm{~Hz}, 1 \mathrm{H}, \mathrm{CHOSi}), 6.08(\mathrm{dd}$, $J=15.8,7.9 \mathrm{~Hz}, 1 \mathrm{H},=\mathrm{C} \underline{\mathrm{HCHO}}), 6.77(\mathrm{dt}$, $\left.J=15.8,7.2 \mathrm{~Hz}, 1 \mathrm{H}, \mathrm{CH}_{2} \underline{\mathrm{C}}=\right), 7.20-7.45$ $\left(\mathrm{m}, 5 \mathrm{H}, \mathrm{C}_{6} \mathrm{H}_{5}\right)$, and $9.45(\mathrm{~d}, J=7.9 \mathrm{~Hz}, 1 \mathrm{H}$, $\mathrm{CHO}) .{ }^{13} \mathrm{C} \mathrm{NMR}\left(\mathrm{CDCl}_{3}\right): \delta$ in $\mathrm{ppm}$ $\left(\mathrm{CDCl}_{3}=77.5 \mathrm{ppm}\right.$, reference): $0.5\left(\mathrm{SiCH}_{3}\right)$, $44.1\left(\mathrm{CH}_{2}\right), 74.0$ (CHOSi), 126.1-128.8 and $144.2 \quad\left(\mathrm{C}_{6} \mathrm{H}_{5}\right), \quad 135.3$ (= $\left.\underline{\mathrm{CHCHO}}\right), 155.1$ $\left(\mathrm{CH}_{2} \mathrm{CH}=\right.$ ), and 194.3 (CHO); IR (in $\mathrm{CCl}_{4}$ solution): $1690(\mathrm{C}=\mathrm{O}), 1650(\mathrm{C}=\mathrm{C}), 1250$ $(\mathrm{Si}-\mathrm{C}), 970(\mathrm{C}-\mathrm{H})$, and $840 \mathrm{~cm}^{-1}(\mathrm{Si}-\mathrm{C})$.

\section{Analyses}

${ }^{1} \mathrm{H}$ and ${ }^{13} \mathrm{C}$ NMR spectra were recorded with a Varian XL-200 spectrometer. IR spectra were recorded with a JASCO IR Report 100 spectrometer. Molecular weight was determined by gel permeation chromatography (GPC) in tetrahydrofuran as the eluent on a Tosoh HLC-803D instrument equipped with gel packed columns (TSKgel G5000-, G4000-, G3000-, and G2000-HXL or G3000-, G2500-, and G1000-HXL) and a differential refractometer. Molecular weight was calibrated using standard polystyrenes.

\section{RESULTS AND DISCUSSION}

\section{Aldol-GTP of E- and Z-BdTMS}

$E$ - or $Z$-BdTMS could be prepared in more than $99 \%$ purity and aldol-GTP of $E$ - or $Z$-BdTMS was examined. The results are summarized in Table III (runs 1-6). AldolGTP of E-BdTMS produced polymer quantitatively even at $-78^{\circ} \mathrm{C}$ (runs 1 and 2). Number-averaged molecular weight $\left(M_{n}\right)$ was 
roughly in accord with the value calculated from the ratio of $[\mathrm{BdTMS}]_{0} /[\mathrm{AAld}]_{0}$ on the assumption of ideal aldol-GTP (namely living polymerization). However, aldol-GTP of $Z$ BdTMS gave neither a polymer nor $1: 1$ aldol adduct of BdTMS and AAld (run 6). Aldol-GTP of $E$ - and $Z$-BdTMS mixture gave a polymer in an yield which is approximate to the value of $E$ content in the mixture (runs 3-5). Only Z-BdTMS was recovered unchanged from the polymerization mixture. It was clear that aldol-GTP of Z-BdTMS proceeded hardly compared with that of $E$-BdTMS, although Z-BdTMS was slightly polymerized on the aldol-GTP of $E$ - and $Z$-BdTMS mixture (runs 4 and 5).

\section{Different Reactivities of $E$ - and Z-BdTMS}

A reaction of $E$ - or $Z$-BdTMS with excess benzaldehyde in the presence of $\mathrm{ZnBr}_{2}$ was followed by GPC measurement of an aliquot of the reaction mixture at different times. This reaction corresponds to the initiation of aldolGTP of BdTMS. Figure 1 shows time-consumption curves on the reaction. E-BdTMS reacted immediately with benzaldehyde to give $1: 1$ aldol adduct. The adduct could be isolated by distillation and identified as 5-phenyl-5-trimethylsiloxy-2-pentenal by NMR. The adduct could be used to initiate the aldol-GTP of BdTMS to yield the polymer with narrow molecular weight distribution. The reaction of Z-BdTMS with benzaldehyde was slower than

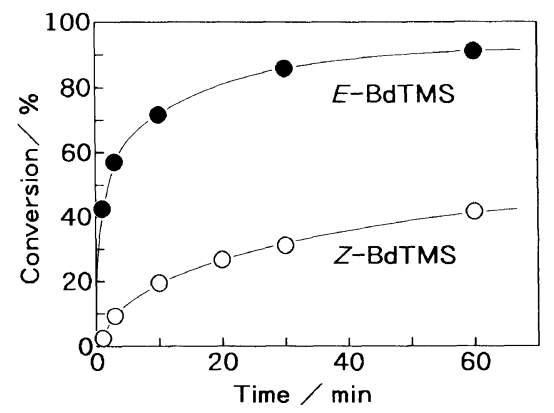

Figure 1. Aldol reaction of $E$ - or $Z$-BdTMS with BAld in the presence of $\mathrm{ZnBr}_{2}$ in benzene at $30^{\circ} \mathrm{C}$ : [BdTMS $]_{0}$, $1.0 \mathrm{moll}^{-1}$; [BAld $]_{0}, 5.0 \mathrm{moll}^{-1} ;\left[\mathrm{ZnBr}_{2}\right]_{0}, 0.1 \mathrm{moll}^{-1}$. that of $E$-BdTMS under the same conditions. However, the product was the same $1: 1$ aldol adduct as that from $E$-BdTMS. That $Z$ BdTMS also reacted with benzaldehyde may be caused by the different reaction conditions from those of polymerization.

Figure 2 shows GPC curves on a equimolar reaction of $E$ - or $Z$-BdTMS with the $1: 1$ aldol adduct prepared from BdTMS and benzaldehyde. The reaction is essentially the same as the propagation of aldol-GTP of BdTMS. $E$-BdTMS reacted with the $1: 1$ aldol adduct to give $2: 1$ (dimer) and $3: 1$ adduct (trimer), while Z-BdTMS hardly reacted with the $1: 1$ aldol adduct under the same conditions. Thus, different reactivities of geometrical isomers of BdTMS were clearly observed on the model reaction corresponding to the initiation and propagation of aldol-GTP.

\section{Aldol-GTP of E- and Z-MeBdTMS \\ $E$ - or $Z$-MeBdTMS could be prepared in}

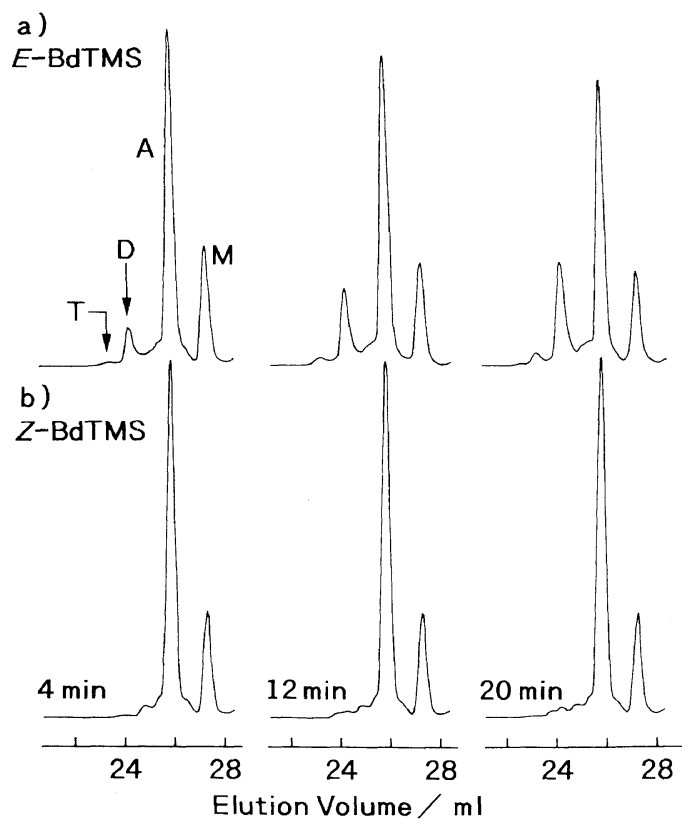

Figure 2. Aldol reaction of $E$ - or $Z$-BdTMS with $1: 1$ aldol adduct in the presence of $\mathrm{ZnBr}_{2}\left(1.9 \mathrm{moll}^{-1}\right.$ solution in diethyl ether) in toluene at $30^{\circ} \mathrm{C}: \mathrm{M}$, monomer; $\mathrm{A}, 1: 1$ aldol adduct; $\mathrm{D}$, dimer; $\mathrm{T}$, trimer; [BdTMS $]_{0}, 0.72 \mathrm{moll}^{-1}$; $[1: 1 \text { aldol adduct }]_{0}, 0.72 \mathrm{moll}^{-1} ;\left[\mathrm{ZnBr}_{2}\right]_{0}, 0.072 \mathrm{moll}^{-1}$. 
more than $99 \%$ purity, and each aldol-GTP was examined. The results are summarized in Table III (runs 7-9). Aldol-GTP of $E$ MeBdTMS, as well as that of $E$-BdTMS, gave its polymer in a good yield (runs 7 and 8). However, aldol-GTP of Z-MeBdTMS (run 9) gave no product under the same conditions of run 8 . It was clearly confirmed that $E$ - and $Z$-isomers of MeBdTMS, as well as BdTMS, showed different reactivities for the aldol-GTP. The reactivities of these isomers for the aldol-GTP seem to depend not on 3-substituent but the geometry of conjugated diene skeleton of monomer.

\section{Aldol-GTP of E- and Z-PhBdTMS Mixture}

PhBdTMS was obtained as a mixture of $E$ - and $Z$-isomers by our procedure, and aldol-GTP of PhBdTMS was carried out without separation of the mixture. The results are summarized in Table III (runs 10-12). The molecular weight distribution of the obtained polymer was fairly narrow. $M_{n}$ of the polymer was not consistent with the value calculated from the ratio of [total $\mathrm{PhBdTMS}]_{0} /[\mathrm{AAld}]_{0}$, but with that from the ratio of $[E-$ PhBdTMS $]_{0} /[\text { AAld }]_{0}$ (runs $10-12$ ). Only the $Z$-isomer was recovered from the polymerization mixture. In run 12 the same amount of PhBdTMS as the first feed (run 11) was added to the polymerization mixture. $M_{n}$ increased from 3800 to 7100 as shown in Figure 3. The increment of $M_{n}$ was in agreement with that of $E$-PhBdTMS in the second feed monomer. These results suggest that only $E$-isomer in the feed monomer mixture may be polymerized on the aldol-GTP. Aldol-GTP of PhBdTMS was followed by ${ }^{1} \mathrm{H}$ NMR measurement of the

Table III. Aldol-GTP of BdTMS, MeBdTMS, and PhBdTMS with AAld and $\mathrm{ZnBr}_{2}$ in toluene

\begin{tabular}{|c|c|c|c|c|c|c|c|c|c|c|c|c|}
\hline \multirow[t]{2}{*}{ Run } & \multirow[t]{2}{*}{ Monomer } & \multirow[t]{2}{*}{$(E / Z)$} & \multirow{2}{*}{ Method $^{\mathbf{b}}$} & \multirow{2}{*}{\multicolumn{2}{|c|}{$\begin{array}{ll}{[\mathrm{M}]_{0}^{\mathrm{a}} \quad[\mathrm{I}]_{0}^{\mathrm{a}}} \\
\\
\times 10^{2} \\
& \mathrm{moll}^{-1}\end{array}$}} & \multirow[t]{2}{*}{$\begin{array}{l}{[\mathrm{C}]_{0}^{\mathrm{a}}} \\
\times 10^{2} \\
\end{array}$} & \multirow{2}{*}{$\frac{\text { Temp }}{{ }^{\circ} \mathrm{C}}$} & \multirow{2}{*}{$\frac{\text { Time }}{\mathrm{h}}$} & \multirow{2}{*}{$\begin{array}{c}\text { Yield } \\
\%\end{array}$} & \multicolumn{2}{|c|}{$M_{n} \times 10^{-3}$} & \multirow[t]{2}{*}{$M_{w} / M_{n}$} \\
\hline & & & & & & & & & & Calcd $^{\mathrm{c}}$ & Obsd $^{d}$ & \\
\hline 1 & BdTMS & $(99 / 1)$ & Hom & 1.00 & 3.3 & 10.0 & 0 & 1 & 95 & 4.0 & 4.5 & 1.51 \\
\hline 2 & BdTMS & $(99 / 1)$ & Hom & 1.00 & 1.0 & 3.0 & -78 & 61 & 91 & 13.0 & 13.7 & 1.36 \\
\hline 3 & BdTMS & $(73 / 27)$ & Het & 1.00 & 3.4 & 3.4 & 0 & 1 & 70 & 2.9 & 4.3 & 1.42 \\
\hline 4 & BdTMS & $(54 / 46)$ & Het & 1.00 & 3.3 & 3.3 & 0 & 1 & 64 & 2.7 & 3.3 & 1.43 \\
\hline 5 & BdTMS & $(50 / 50)$ & Hom & 1.00 & 3.3 & 10.0 & 0 & 1 & 56 & 2.4 & 2.5 & 1.47 \\
\hline 6 & BdTMS & $(0 / 100)$ & Hom & 1.00 & 3.3 & 10.0 & 0 & 2 & 0 & & & \\
\hline 7 & MeBdTMS & $(99 / 1)$ & Het & 1.48 & 1.5 & 1.7 & 0 & 3 & 81 & 12.6 & 10.0 & 1.25 \\
\hline 8 & MeBdTMS & $(99 / 1)$ & Hom & 2.57 & 0.8 & 2.7 & -78 & 20 & 88 & 44.0 & 17.7 & 1.28 \\
\hline 9 & MeBdTMS & $(0 / 100)^{e}$ & Hom & 2.57 & 0.9 & 2.7 & -78 & 24 & 0 & & & \\
\hline 10 & PhBdTMS & $(53 / 47)$ & Het & 1.05 & 1.0 & 3.0 & 0 & 1 & 50 & $12.2^{\mathrm{f}}$ & $10.0^{\mathrm{g}}$ & 1.20 \\
\hline 11 & PhBdTMS & $(55 / 45)$ & Het & 1.00 & 3.2 & 3.2 & 0 & 0.25 & $-^{\mathbf{h}}$ & $3.9^{f}$ & $3.8^{\mathrm{g}}$ & 1.22 \\
\hline 12 & $\mathrm{PhBdTMS}$ & $(55 / 45)$ & Het & $-^{\mathbf{h}}$ & $-^{\mathrm{h}}$ & $-^{\mathbf{h}}$ & 0 & 0.25 & 52 & $7.8^{f}$ & $7.1^{\mathrm{g}}$ & 1.31 \\
\hline
\end{tabular}

a $\mathrm{M}$, monomer; I, $p$-anisaldehyde; $\mathrm{C}, \mathrm{ZnBr}_{2}$.

b Het, heterogeneous polymerization with solid $\mathrm{ZnBr}_{2}$; Hom, homogeneous polymerization with $\mathrm{ZnBr}_{2}$ solution in diethyl ether.

c Calculated from $[\mathrm{M}]_{0} /[\mathrm{I}]_{0} \times$ Yield $/ 100 \times(\mathrm{mol} \mathrm{wt}$ of monomer $)+(\mathrm{mol}$ wt of AAld $)$.

d Determined by GPC, calibrated with standard polystyrene samples.

e Containing 16\% 3-methyl-1-trimethylsiloxy-2-butene as an impurity.

f Calculated from $[E \text {-monomer }]_{0} /[\mathrm{I}]_{0} \times(\mathrm{mol}$ wt of monomer $)+(\mathrm{mol}$ wt of AAld $)$.

g Corrected by the $Q$-factor method.

${ }^{\text {h }}$ Runs 11 and 12 were conducted in a series of experiments; the same amount of PhBdTMS as run 11 was succesively added to the polymerization mixture. 
polymerization mixture, and signals due to unchanged monomer were detectable. Figure 4 shows change of $Z$ content in unchanged

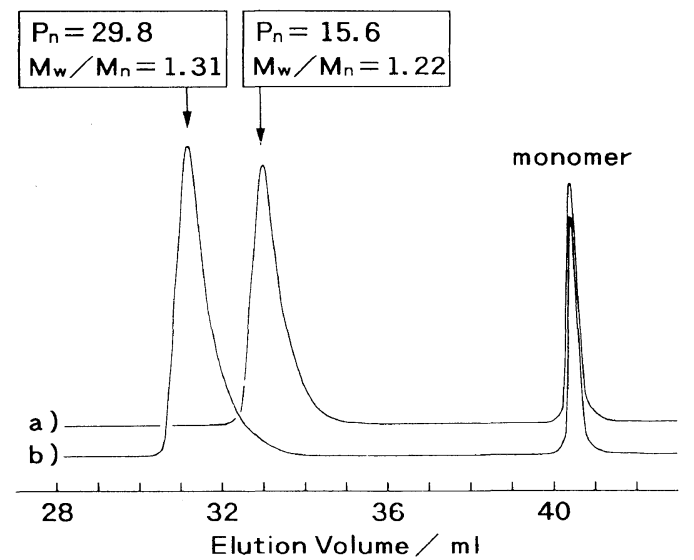

Figure 3. GPC profile on aldol-GTP of PhBdTMS: (a) after $15 \mathrm{~min}$ (run 11 in Table III); (b) after additional PhBdTMS was added to react for 15 min (run 12 in Table III).

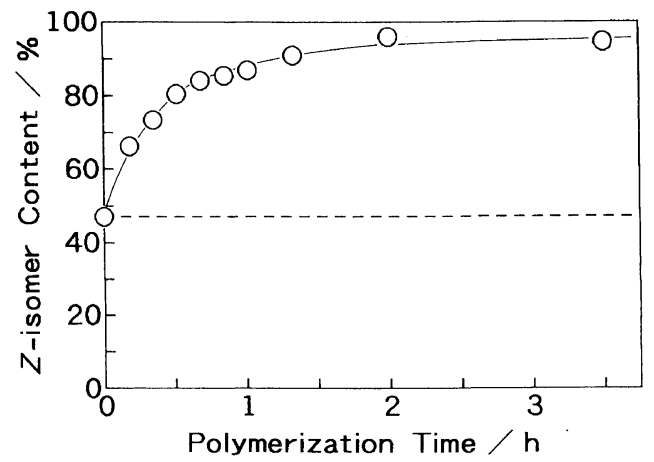

Figure 4. Aldol-GTP of PhBdTMS (E/Z, 53/47) with AAld and $\mathrm{ZnBr}_{2}$ in benzene- $d_{6}$ at $35^{\circ} \mathrm{C}$ : $[\mathrm{PhBdTMS}]_{0}$, $0.4 \mathrm{moll}^{-1} ;$ [AAld $]_{0}, 24 \mathrm{mmoll}^{-1} ;\left[\mathrm{ZnBr}_{2}\right]_{0}, 26 \mathrm{mmoll}^{-1}$. monomer with time during the aldol-GTP of PhBdTMS. $E$-isomer was rapidly converted to its polymer, while $Z$-isomer was not consumed.

The geometry of $Z$-isomer is thus not preferable to the aldol-GTP. Possible ball and stick models of transition state for the propagation of the aldol-GTP are illustrated in Figure 5. A substituent at 3-position of monomer and a chain end formyl group coordinated with $\mathrm{ZnBr}_{2}$ may be located in opposite directions to make steric crowding minimum.

\section{Transition State of Aldol-GTP}

Propagation of aldol-GTP involves at least three processes ${ }^{4}$ : (1) activation of a formyl group in a propagating chain end (=dormant) by coordination with $\mathrm{ZnBr}_{2}$, (2) nucleophilic addition of an incoming monomer to the activated formyl group, inducing a new carbon-carbon bond, (3) transfer of a trimethylsilyl group from the monomer to the formyl oxygen, resulting in the regeneration of a new formyl group on the chain end. Process (3) is called "group transfer".

If processes (2) and (3) occur independently and the geometry of the isomers is freely permitted to change during the propagation, different behavior of $E$ - and $Z$-isomers would not be observed on the aldol-GTP. Therefore it seems that bifunctional interaction is required for the building up of a possible transition state for the propagation as well as the initiation. Once the transition state is built up, processes (2) and (3) will occur smoothly a) $E$-isomer

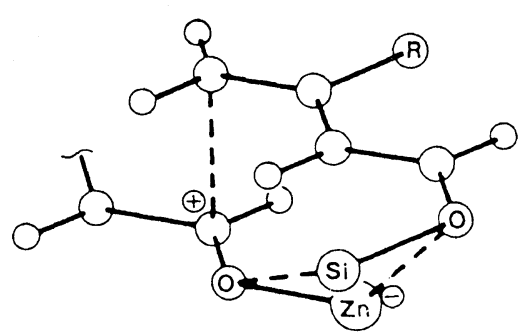

b) Z-isomer

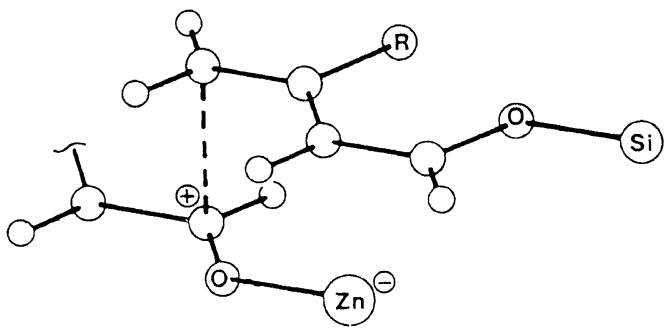

Figure 5. Possible ball and stick models of transition states for the propagation of aldol-GTP. 
via a concerted mechanism.

The selective aldol-GTP for $E$-isomer can be explained as $E$-isomer is able to build up the bicyclic transition state (I in Scheme 2). In the transition state I, the $p$ orbital of 4-position carbon of monomer overlaps the empty $p$ orbital of the formyl carbocation, and the coplanarity of the conjugated system is maintained as much as possible. Although two such conditions are imposed on I, there is little problem for the $E$-isomer. The $Z$-isomer can not form a similar transition state, because the trimethylsilyl group of $Z$-isomer and formyl oxygen in propagating chain end are far apart (III in Scheme 2). There is no interaction promoting "transfer" of trimethylsilyl group even if $\mathrm{ZnBr}_{2}$ activates the propagating chain end.

At present, however, it is ambiguos whether processes (2) and (3) occur together or stepwise. Even if processes (2) and (3) occur stepwise, a similar cyclic transition state (II in Scheme 2) must be required sooner or later. After monomer and end formyl groups form a carbon-carbon bond, the trimethylsilyl group must be transferred from the monomer to the formyl oxygen. Of course, this occurs only if steric arrangement of a cationized allylic moiety of II maintaines that of the $E$-isomer. Otherwise, $Z$-isomer will be also polymerized through geometrical isomerization of a cationized allylic moiety. The bicyclic transition

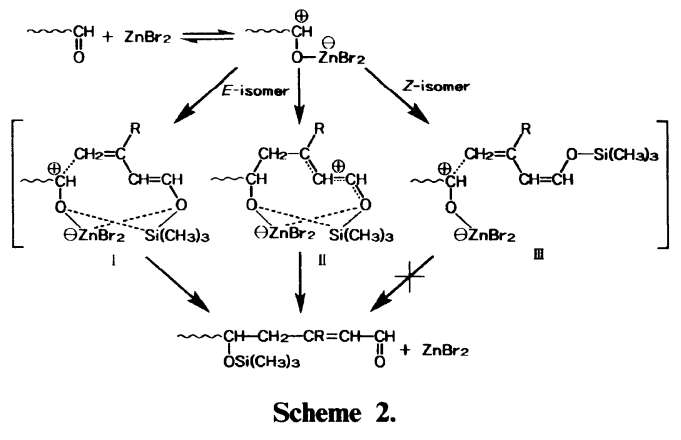

state, I or II, is a valid explanation for the different polymerizabilities of geometrical isomers of BdTMS and derivatives for aldol-GTP.

\section{REFERENCES}

1. T. Hirabayashi, T. Ito, and K. Yokota, Polym. J., 20, 1041 (1988).

2. T. Hirabayashi, T. Kawasaki, and K. Yokota, Polym. J., 22, 287 (1990).

3. H. Sumi, T. Hirabayashi, Y. Inai, and K. Yokota, Polym. J., 24, 669 (1992).

4. H. Sumi, A. Suzuki, T. Hirabayashi, Y. Inai, and K. Yokota, Polym. J., 26, 705 (1994).

5. Y. Mori, H. Sumi, T. Hirabayashi, Y. Inai, and K. Yokota, Macromolecules, 27, 1051 (1994).

6. S. Danishefsky and T. Kitahara, J. Org. Chem., 40, 538 (1975).

7. G. Demailly, J. B. Ousset, and C. Mioskowski, Tetrahedron Lett., 25, 4647 (1984).

8. C. J. Schmidle and P. G. Barnett, J. Am. Chem. Soc., 72, 3209 (1956). 